\title{
Surface treated bagasse fiber ash on rheological, mechanical properties of PLA/BFA biocomposites
}

\author{
Watcharin Sitticharoen ${ }^{1 *}$, Chet Uthiyoung ${ }^{1}$, Nateechai Passadee ${ }^{1}$ and Chanokpol Wongprom ${ }^{1}$ \\ ${ }^{1}$ Department of Industrial Engineering, Faculty of Engineering, Rajamangala University of Technology \\ Lanna - RMUTL, Muang, Chiang Mai, Thailand \\ *wsitticharoen@yahoo.com
}

\begin{abstract}
The use of silica based bagasse fiber ash (BFA) as a reinforcing filler in polylactic acid (PLA) biocomposites was examined. The effects of surface-treated BFA on the rheological, swelling behavior, and mechanical properties and water absorption of biocomposites were studied. BFA was treated using a silane coupling agent (Bis-[3-(triethoxysilyl)propy]-tetrasulfide). Composites with BFA were varied from 5 to $25 \mathrm{wt} . \%$. The PLA/BFA composite melts were pseudoplastic non -Newtonion fluid and exhibited a shear thinning behavior. The viscosity of the surface-treated BFA biocomposites was higher than that of the untreated. The viscosity of the composites decreased with increasing BFA content and shear rate. The extrudate swell of the composites increased with increasing shear rate, whereas it decreased with increasing BFA content and die temperature. The extrudate swell tended to be suppressed when surface-treated BFA was used. Silane treated BFA composites showed improvement in their mechanical properties, and exhibited significantly reduced water absorption.
\end{abstract}

Keywords: bagasse fiber ash, polylectic acid, rheology, extrudate swell, mechanical properties.

\section{Introduction}

Nowadays, plastics are used at very high rates all over the world. Plastics are strong, durable and long-lasting, and have become a major environmental problem. The use of polymer composites from renewable resources has advantages over synthetic resources, particularly as a solution to the environmental problem caused by plastic waste. Thus, bio-based composite materials have become a hot issue for study and industrial research. Polylactic acid (PLA) is the first commodity plastic produced from annually renewable resources due to its great mechanical strength, thermal plasticity, easy processability and compostable polymer. Besides its advantages, PLA also has some practical shortcomings, such as its low elongation at break, melt strength, and expensive price. To address these disadvantages, PLA is modified by a variety of methods including reinforcement with nature fibers ${ }^{[1-3]}$. Natural fiber has gained much attention due to its low price, high toughness, easy availability and biodegradability ${ }^{[4]}$. Bagasse ash is a by-product from burning sugar cane, and is used as fuel for power generation within the sugar factory. The resulting bagasse ash represents approximately $0.62 \%$ of the sugarcane weight ${ }^{[5]}$, or 656,000 tons per year in Thailand, and is now becoming an environmental burden ${ }^{[6]}$. Bagasse ash can be considered an important potential reinforcing filler for polymer composites. Agunsoye and Aigbodion ${ }^{[7]}$ studied the effect of carbonized bagasse particles (CBp) on mechanical properties of recycled low-density polyethylene (RLDPE) composites, and found that the tensile, bending strength and hardness properties of the composites increased with increasing carbonized bagasse content. Aigbodoin et al. ${ }^{\left[{ }^{8]}\right.}$ found that recycled low-density polyethylene (RLDPE) filled with carbonized bagasse ash particles increased the wear resistance of the composites greatly. Sitticharoen et al. ${ }^{[9]}$ suggested that bagasse fiber ash (BFA) particles contained $78-80 \%$ of silica which could be used as reinforcing or extending filler in recycled high-density polyethylene composites, and found that the tensile and flexural modulus and hardness properties of the BFA treated composites with vinyltrimethoxysilane were higher than that of the untreated particles. Additionally, Sitticharoen et al. ${ }^{[9]}$ found that BFA particle's composites exhibited a pseudoplastic non-Newtonoin flow behavior. Moreover, bagasse fiber ash (BFA) can be utilized as a property enhancing filler in natural rubber (NR) compounds ${ }^{[10]}$. An understanding of the rheological behavior of fiber/polymer composites is beneficial to the design of polymer processing equipment, and can be used to predict final polymer products and to correlate with the mechanical properties of the composites. Awal et al. ${ }^{[1]}$ studied the cellulose fibers on rheological and mechanical properties of polylactic acid (PLA) biocomposites, and found that the tensile modulus, tensile strength and impact strength properties of the biocomposites increased significantly with increasing bioadimide and its biocomposites exhibited a shear thinning behavior. Dangtungee et al. ${ }^{[12]}$ investigated the rheology behavior and extrudate swell of polylactic acid (PLA) filled with nanoclay and found that its composites exhibited a pseudoplastic behavior as the shear stress and die swell increased with increasing shear rate.

The objective of this study is to develop biocomposites using PLA as matrix filled with surface-treated BFA obtained from agricultural waste, give value-added applications to 
an undervalued material and investigate its melt rheology, extrudate swell, mechanical properties and water absorption of the produced biocomposites.

\section{Materials and Methods}

\subsection{Raw materials}

1. Polylactic acid (PLA 2003D) with a melt flow rate of $6 \mathrm{~g} / 10 \mathrm{~min}$ was supplied in granular form by NatureWorks LLC (Minnetonka, MN, USA);

2. Bagasse fiber ash (BFA) was supplied by the biomass power plant station of Kaset Thai International Sugar Corp Co., Ltd. (Nakhonsawan, Thailand). The dimensions and shape of the BFA particles were examined using a JEOL JSM-5910LV SEM machine (Tokyo, Japan), and found that BFA had round-shaped particles with relatively smooth surfaces. The average particle size of the BFA used was $53 \mu \mathrm{m}$. An X-ray fluorescence spectrometer (XRF, MESA-500W, Horiba, Japan) was used for analyzing the chemical compositions of the BFA. It was found that the major component of BFA was $\mathrm{SiO}_{2}$, which constituted about $80 \%$ of BFA.

\subsection{Surface treatment of BFA}

Bis-[3-(triethoxysilyl)-propy]-tetrasulfide (Couplink 89), supplied by Behn Meyer Chemical (T) Co., Ltd. (Bangkok, Thailand), was used as a chemical coupling agent for BFA surface treatment. A solution of $2.0 \mathrm{wt} \%$ silane coupling agent was slowly dropped into $100 \mathrm{ml}$ of ethanol and then stirred for 30 minutes. $100 \mathrm{~g}$ of the BFA particles were then added into the solution and stirred for $15 \mathrm{~min}$ to ensure a uniform distribution of the coupling agent on the BFA surfaces. After treatment, the BFA particles were dried in an oven at $100{ }^{\circ} \mathrm{C}$ for $24 \mathrm{~h}$.

\subsection{Preparation and fabrication of PLA/BFA composites}

PLA granules were dry-blended with desired amounts of BFA particles and silane coupling agent using a high speed mixer for $2 \mathrm{~min}$ before being melt-blended in a single-screw extruder (Model SMC500, Thailand) to obtain PLA/BFA composites. The BFA content was varied from 0 to $25 \mathrm{wt} \%$. The blending temperature profiles on the extruder were $150,160,170$ and $180^{\circ} \mathrm{C}$ from hopper to die zones and the screw rotation speed was $40 \mathrm{rpm}$. A two-strand die having a diameter of $3 \mathrm{~mm}$ for each strand and coupled with a pelletizing unit was used to produce the PLA/BFA composites pellets, which were held in an oven for $24 \mathrm{~h}$ at $80{ }^{\circ} \mathrm{C}$. The PLA/BFA composites were injection-molded at $185^{\circ} \mathrm{C}$ using a HYF-1000 injection moulding machine (Charoen Tut, Samut Prakan, Thailand), to produce test specimens for determinations of their mechanical properties.

\subsection{Rheological and extrudate swell measurements and apparatus}

Melt rheology and extrudate swell of neat PLA and PLA/BFA composites samples were studied by using an extrusion rheometer and connected at the end of a single screw extruder as shown in Figure 1. A single screw extruder

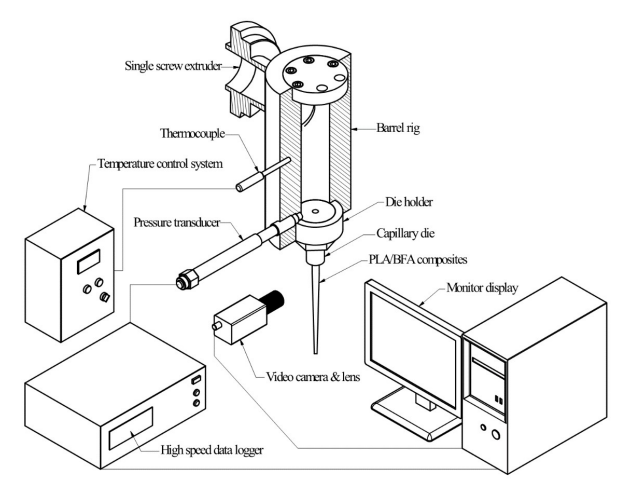

Figure 1. Experimental arrangement for measuring the flow properties and extrudate swell of PLA/BFA composite melts in a single-screw extruder.

(RMUTL-SE001 MUSHIKNG PolyLab) supplied by RMUTL (Chiang Mai, Thailand) was varied to investigate the melt rheological and extrudate swell behavior of the composites. The barrel rig was assembled at the end of the single screw extruder. The exact length-to-diameter (L/D) ratio of the barrel was $600 / 25 \mathrm{~mm} / \mathrm{mm}$, and the temperature profiles on the extruder from hopper to die zones were $150,170,180$ and $160^{\circ} \mathrm{C}$, respectively. The die used in this work was $40 \mathrm{~mm}$ in length and $6 \mathrm{~mm}$ in diameter. The die temperature was varied from 160 to $170^{\circ} \mathrm{C}$. The rotational speed of the screw was varied from 3 to $20 \mathrm{rpm}$ in order to generate shear rates from 8.0 to $49.4 \mathrm{~s}^{-1}$. The flow characteristics of the neat PLA and PLA/BFA composite melts were evaluated during extrusion from the barrel through a capillary die in the single screw extruder. The pressure drop at the entrance was recorded in real time using a high speed data-logging and recording system and a personal computer through a visual basic program. The pressure drop at the die entrance was used to calculate the shear stress. The volumetric flow rate from the extruder was varied by changing the rotational speed of the screw and was used to calculate the shear rate. It should be noted that Bagley corrections were not applied to the flow data generated in this work due to two reasons: First, the wall shear stress and wall shear rate data were used solely for comparative reasons to illustrate the magnitude of the changes observed in the flow characteristics of the materials as a function of the rotational speed of the screw and the BFA content. Second, the die dimensions used were constant throughout this work which implies that Bagley's corrections could be neglected in this case. The apparent wall shear stress $\left(\tau_{\text {app }}\right)$ of the capillary can be expressed by Equation $1^{[9,11-12]}$,

$$
\tau_{\text {app }}=\frac{\Delta P R}{2 L}
$$

where $\Delta P$ is the pressure drop along the die, $\mathrm{L}$ is the length of the die. The apparent wall shear rate $\left(\gamma_{\text {app }}^{\circ}\right)$ is defined as:

$$
\gamma_{\text {app }}^{\circ}=\left[\frac{3 n+1}{4 n}\right]\left[\frac{4 Q}{\pi R^{3}}\right]
$$

where $\mathrm{Q}$ is the volumetric flow rate along the capillary die, and $\mathrm{n}$ is the power law index. The apparent viscosity $\left(\eta_{\text {app }}\right)$ of the PLA/BFA composites is practically expressed by the 
ratio of the apparent wall shear stress $\left(\tau_{\text {app }}\right)$ to the apparent wall shear rate $\left(\gamma_{\text {app }}^{\circ}\right)$.

Extrudate swell of neat PLA and PLA/BFA composites was measured using a color video-camera (WATASHI CCD and 700TVL lines), and a high-resolution macro-zoom lens (WLA008) was used to record the flows for further calculations of extrudate swell. All results were recorded and displayed in real time using a personal computer and used a motic images plus 2.0 ML program for extrudate swell measurement. The extrudate swell (S) is reported as the percentage of extrudate swell $(\% \mathrm{~S})$, as follows ${ }^{[13]}$ :

$$
\% S=\frac{\left(D_{e x t}-D_{d}\right) \times 100}{D_{d}}
$$

Where $\mathrm{D}_{\text {ext }}$ and $\mathrm{D}_{\mathrm{d}}$ are the diameter of the extrudate and the die, respectively.

\subsection{Mechanical properties}

The mechanical properties of neat PLA and PLA/BFA composites were evaluated via tensile, flexural, impact and hardness properties. All the mechanical property results reported in this work were averaged from at least five independent determinations. The tensile test was performed on a Instron universal testing machine (Model Instron 5569, UK) using a crosshead speed of $50 \mathrm{~mm} / \mathrm{min}$ and the test procedure followed the ASTM D638 (2010) specimen Type I. The flexural test was performed according to ASTM D790 (2007) at the test speed of $1 \mathrm{~mm} / \mathrm{min}$. The Izod impact test was conducted in accordance with ASTM D256 (1993) using a Gotech impact tester (Model GT-7045, Taiwan) with the notched side facing the pendulum. The hardness test was assessed using a Durometer Shore D (Model HH-337-11, Japan). The test procedure was specified by ASTM D2240 (2005).

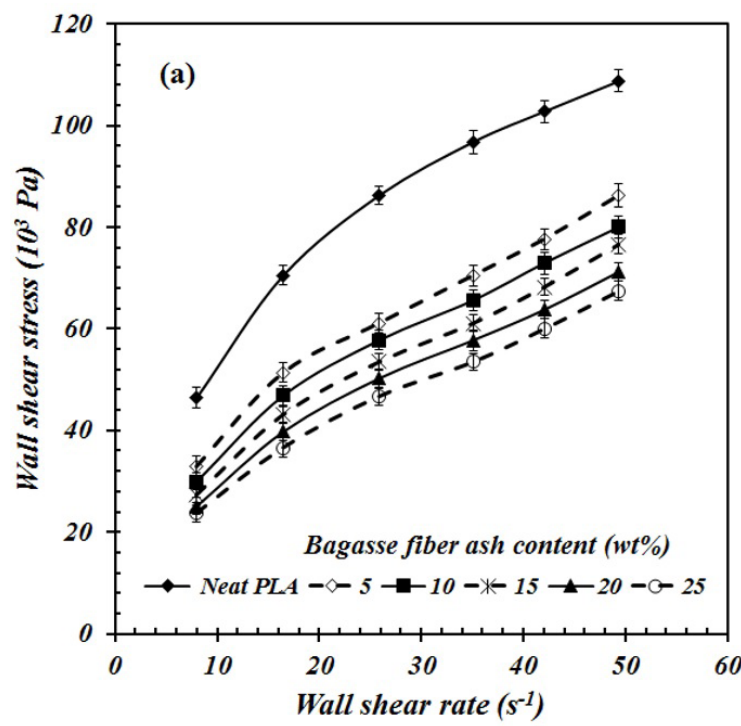

\subsection{Water absorption tests}

Water absorption tests of the composites were conducted following the modified ISO-62 standard. Samples measuring $19 \times 19 \times 3.2 \mathrm{~mm}$ were cut from the head of the tensile test specimens and the cut cross sections were polished. Five specimens were tested in each sample. The samples were immersed in water and the samples were weighed after 2 weeks of water immersion.

\subsection{Scanning Electron Microscopy (SEM) investigations}

Fracture surface analysis is usually required for mechanical testing of the PLA/BFA composites. In this work, fracture surfaces of the PLA/BFA composites were obtained after a 2-min immersions in liquid nitrogen. All the samples were sputter coated with a thin layer of gold before analysis and investigated with JEOL (JSM-5910LV, Tokyo, Japan) SEM machine at $15 \mathrm{kV}$ of accelerating voltage.

\section{Results and Discussion}

\subsection{Rheological properties}

The flow behavior of the composite in the molten state is important to characterize the processing properties of the polymer melt and is usually reported by the flow curve relationship between shear stress and shear rate. Figure 2 shows results of the apparent wall shear stress as a function of the apparent wall shear rate for the neat PLA and PLA/BFA composites at a test temperature of $160{ }^{\circ} \mathrm{C}$ with various content of untreated (a) and surface-treated (b) BFA particles. It can be seen that the neat PLA and its biocomposites exhibited a pseudoplastic non-Newtonion flow behavior as the wall shear stress increased with increasing wall shear rate in a nonlinear manner. At a given wall shear rate, the wall shear stress decreased with increasing BFA content. With increasing BFA filler content, the difference

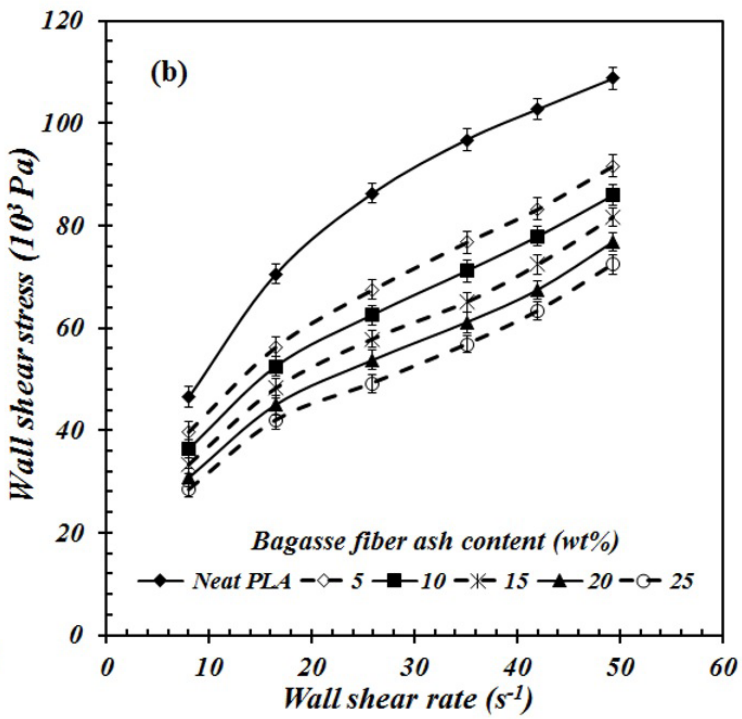

Figure 2. Flow curves of neat PLA and PLA/BFA composites at $160^{\circ} \mathrm{C}$ with various content of untreated (a) and surface-treated (b) BFA particles. 
between the wall shear stress values of PLA/BFA composites with untreated and neat PLA at a given apparent shear rate gradually increased, with the value of PLA/BFA composites with untreated BFA particles being lower than that of neat PLA and the maximum difference between the shear stress values being observed at the filler content of $25 \mathrm{wt} . \%$. Comparison between the results shown for PLA/BFA composites with untreated and surface-treated BFA revealed that, at a given wall shear rate, values of the shear stress for PLA/BFA composites were higher in the case of surfacetreated BFA particles. It was obvious that the apparent shear stress of the PLA/BFA composite melts with a high filler content (25 wt. \%) of untreated BFA particles was $67.5 \times 10^{3}$ $\mathrm{Pa}$, versus $72.4 \times 10^{3} \mathrm{~Pa}$ for surface-treated BFA. This fact can be explained by the surface treatment effect, leading to an increased apparent shear stress. This result was in agreement with Dangtungee et al. ${ }^{[12]}$ who stated that the shear stress values for the PLA composite melts that were surface- treated were higher than those that were untreated.

Figure 3 shows the apparent shear viscosity against the wall shear rate for the neat PLA and PLA/BFA composites at a test temperature of $160^{\circ} \mathrm{C}$ for various concentrations of untreated (a) and surface-treated (b) BFA particles. Generally, the shear viscosity of the neat PLA and its biocomposites gradually decreased with increasing apparent shear rate. These results confirm that all materials exhibited a shear thinning (pseudoplastic) non-Newtonion behavior due to molecular orientation and relaxation of PLA chains under shear deformation, leading to the values of viscosity decreasing. This view could be supported by the work of Sitticharoen et al., Dangtungee et al. and Muksing et al. ${ }^{[9,12-13]}$ who stated that under shear, molecular chains become oriented, relaxation of the chains, and the numbers of entanglement were reduced; as a result of which the viscosity decreases. It is noteworthy that the apparent shear viscosity of the composite melts, both untreated and surface-treated BFA, were found to decrease with increasing BFA content. The viscosity of PLA/BFA composite melts with surface-treated BFA particles became higher than that of untreated BFA particles when the shear rate was increased, and obviously the maximum difference between the viscosity values of PLA/BFA composites observed at the filler concentration were $25 \mathrm{wt} . \%$. This was because the surface-treated BFA particles, resulted in a uniform dispersion of the BFA particles in the polymer matrix and also can be intercalated between PLA molecular chains, which would cause the increase in the melt viscosity of the biocomposites.

\subsection{Extrudate swell behavior}

Figure 4 shows the dependence of the extrudate swell as a function of the apparent shear rate at $160{ }^{\circ} \mathrm{C}$ for the neat PLA and PLA/BFA composites with various content of untreated (a) and surface-treated (b) BFA particles. Extrudate swell of sample materials increased with increasing apparent shear rate in a nonlinear manner. It was observed that at the lower apparent shear rate range $\left(8.0-25.9 \mathrm{~s}^{-1}\right)$, the extrudate swell of the PLA/BFA composite melts sharply increased with increasing apparent shear rate and then gradually increased. This can be attributed to the increase of apparent shear rate, which then increased the force on the composite melts while flowing into the capillary die. This force occurs in the form of an apparent shear stress, which was found to increase with increasing shear rate or extrusion rate. At the higher apparent shear rates $\left(25.9-49.4 \mathrm{~s}^{-1}\right)$, the effect of shear rate was associated with higher extrusion rates generating greater elastic energies stored in the molten polymer flow increases, which caused the enhanced extrudate swell for both composite systems ${ }^{[13-15]}$. The neat PLA showed a greater swelling than that of the PLA/BFA composites with untreated and surface-treated BFA particles.

Apparently, the extrudate swell of the PLA/BFA composites with surface-treated BFA particles was lower than in the case of untreated ones. This could be explained by the fact that the inorganic silica particles present in the
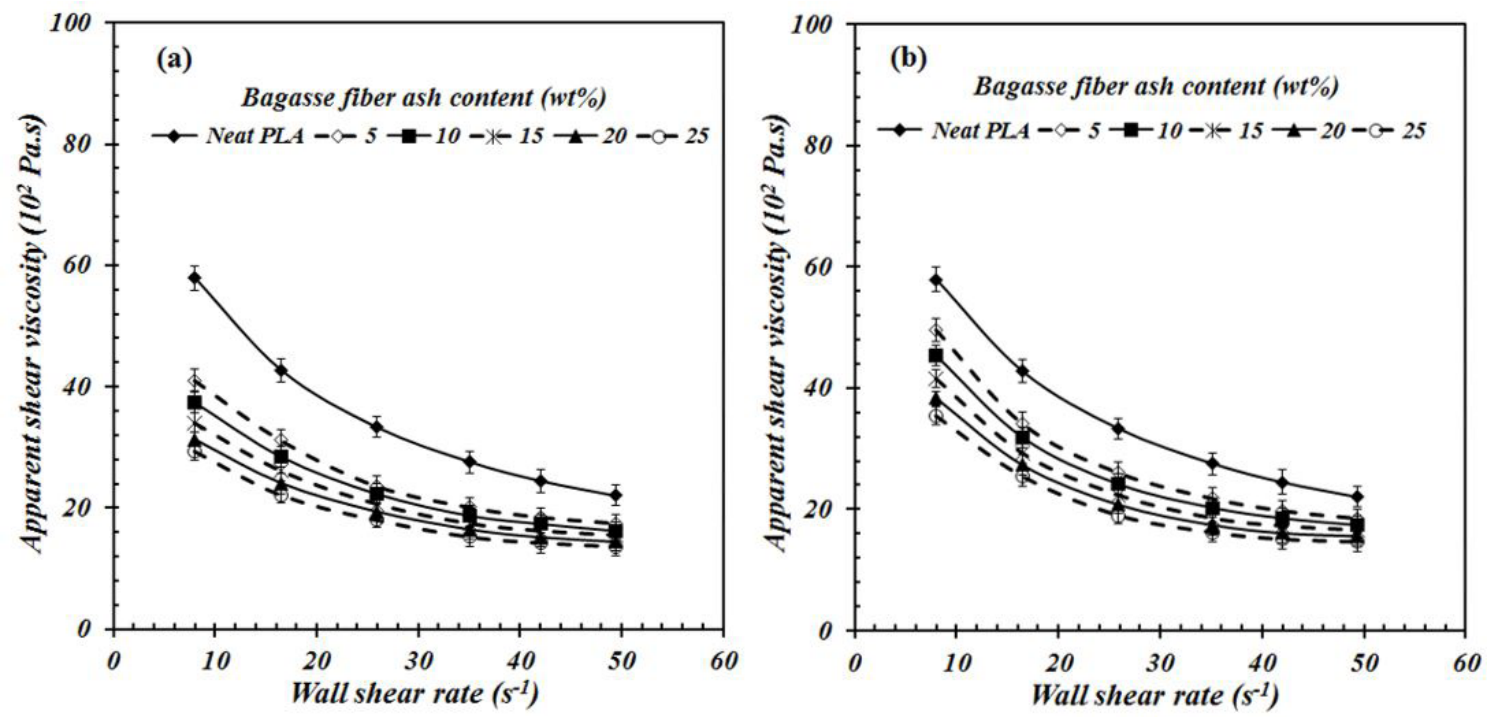

Figure 3. Apparent shear viscosity as a function of wall shear rate for neat PLA and PLA/BFA composites at $160{ }^{\circ} \mathrm{C}$ with various content of untreated (a) and surface-treated (b) BFA particles. 
BFA showed a good dispersion and distribution in the PLA matrix and can be intercalated between PLA chains, resulting in an inhibition of the polymer chain motion by the filler particles, leading to decreased extrudate swell. It was also found that the composites both untreated and surface-treated BFA particles reduced the severity of the extrudate swell with increasing BFA content. This view could be supported by the work of Musking et al. ${ }^{[13]}$, Dangtungee et al. ${ }^{[16]}$ and Liang ${ }^{[17]}$ who stated that the movement of the matrix molecular chains would be made more difficult due to the presence of filler particles and that the elastic recovery would be blocked when the composite melt emerges from the die, leading to a decrease in extrudate swell. Figure 5 shows photographs of extrudates of PLA/BFA composites with 10 wt. $\%$ of untreated (a) and surface-treated (b) BFA particles for different wall shear rates which were taken during extrusion.

Figure 6 illustrates the dependence of the extrudate swell as a function of the apparent shear rate of the neat PLA and PLA/BFA composites with various content of
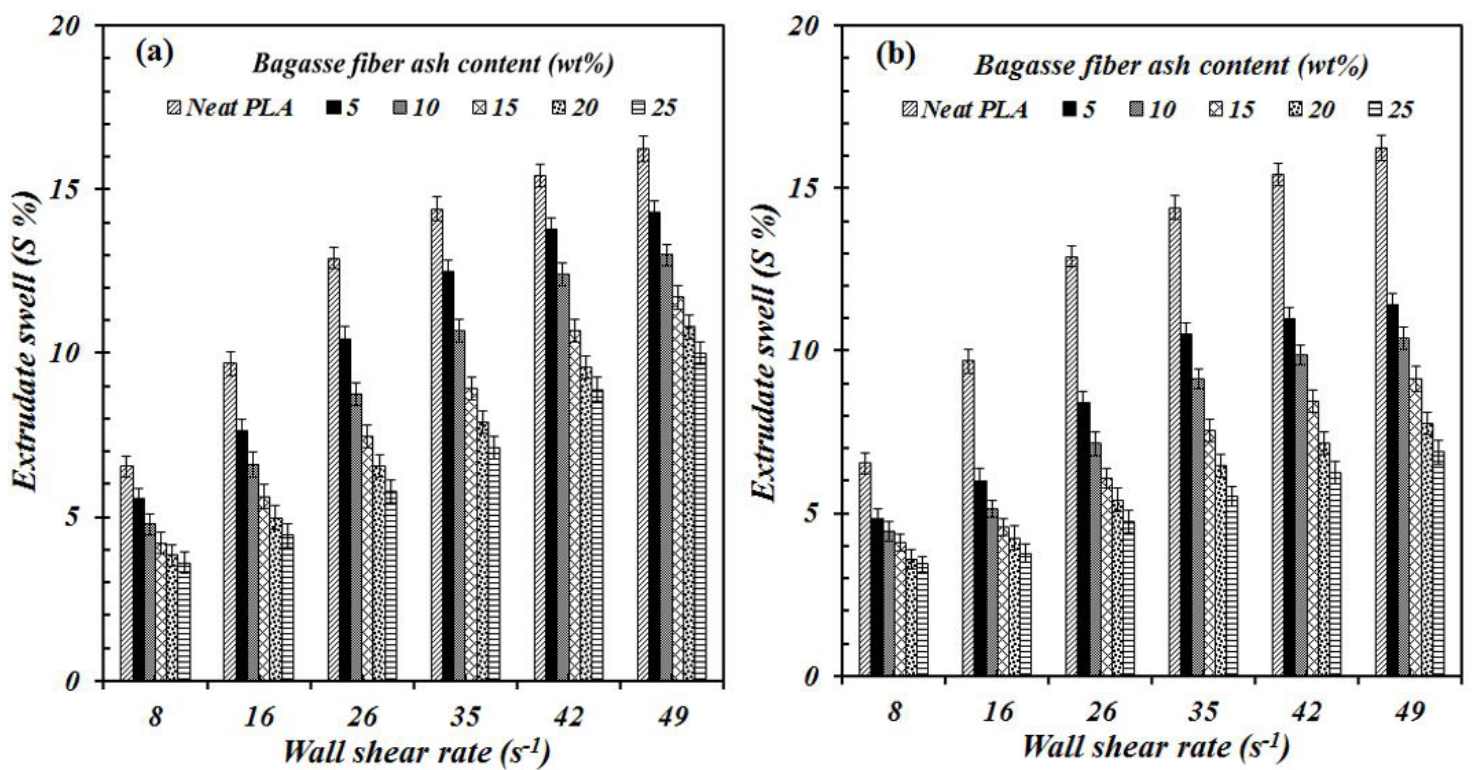

Figure 4. Percentage of extrudate swell as a function of wall shear rate at $160{ }^{\circ} \mathrm{C}$ for neat PLA and PLA/BFA composites with various content of untreated (a) and surface-treated (b) BFA particles.

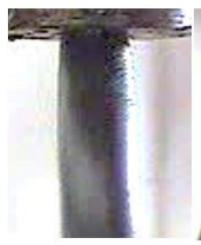

$8 \mathrm{~s}^{-1}$

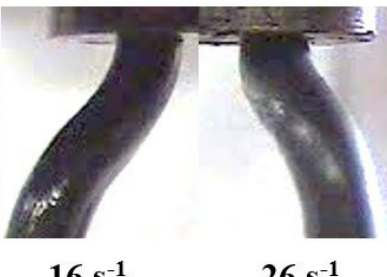

$16 \mathrm{~s}^{-1}$

$26 \mathrm{~s}^{-1}$

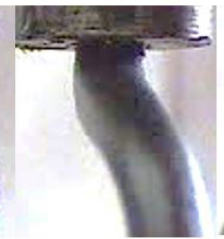

$35 \mathrm{~s}^{-1}$

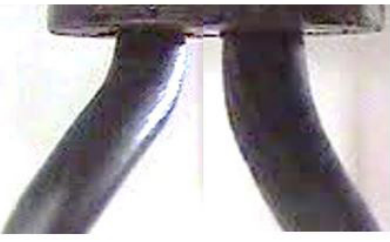

$42 \mathrm{~s}^{-1}$
$49 s^{-1}$

(a)

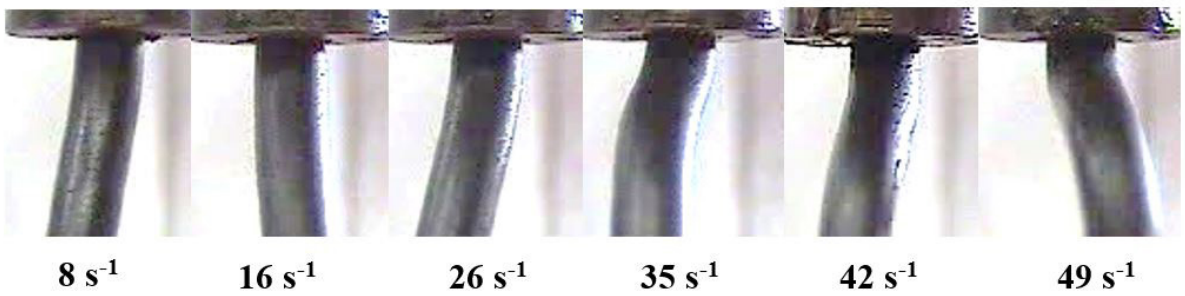

(b)

Figure 5. Shows photographs of extrudates of PLA/BFA composites with $10 \mathrm{wt} . \%$ of untreated (a) and surface-treated (b) BFA particles. 
surface-treated BFA particles for different temperatures. The extrudate swell of the neat PLA and biocomposite melts at various shear rates decreased with a rise of test temperature, and it rose with increasing apparent shear rate. With a rise of temperature, the molecular mobility of the PLA chains will be intensified, and the relaxation process of the composite melt is correspondingly shortened, leading to a reduction of the elastic recovery of the composite melt when it leaves the die. Therefore, the extrudate swell of the biocomposite is extremely reduced ${ }^{[13,18]}$.

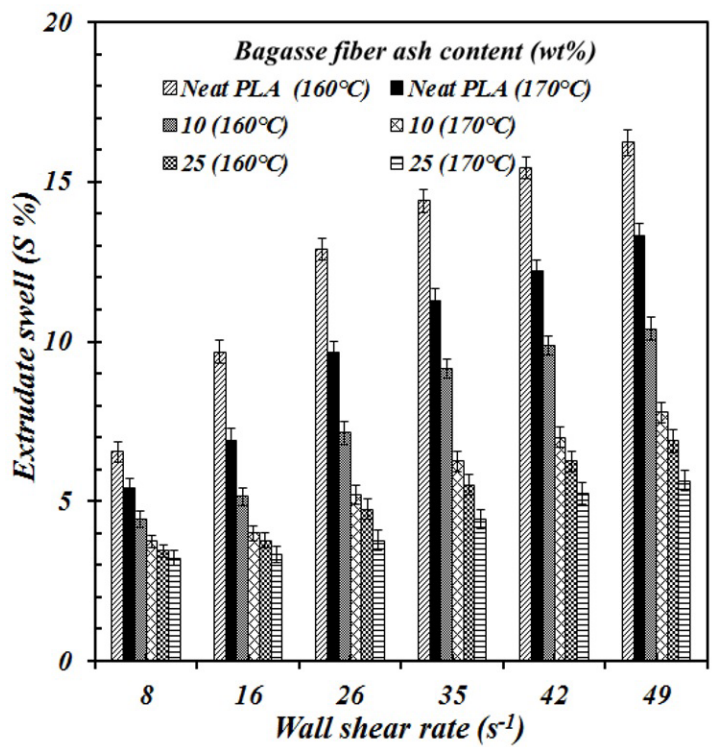

Figure 6. Percentage of extrudate swell as a function of wall shear rate of neat PLA and PLA/BFA composites with various content of surface-treated BFA particles for different temperatures.

\subsection{Mechanical properties}

Figure 7 shows the tensile modulus and flexural modulus of the PLA/BFA composites with untreated and surface-treated BFA particles. It was found that the amount of added reinforcement filler contributes to variation of the tensile and flexural modulus of the composites, both with untreated and surface-treated BFA particles. Obviously, the tensile and flexural modulus of the composites increased progressively when increasing the BFA filler content. Silica-based BFA particles insertion can contribute to an increase of the composite's modulus due to Young's modulus of the BFA particles being higher than the thermoplastic modulus ${ }^{[7,9]}$. The tensile and flexural modulus of both untreated and surface-treated BFA gradually increased when the filler concentration increased up to $25 \mathrm{wt} . \%$. The maximum tensile and flexural modulus of the composites with untreated particles were $4.23 \times 10^{9}$ and $3.95 \times 10^{9}$ $\mathrm{Pa}$, versus $4.61 \times 10^{9}$ and $4.24 \times 10^{9} \mathrm{~Pa}$, respectively, for surface-treated BFA particles. Tensile strength and flexural strength of the composites with untreated and surface-treated BFA particles are shown in Figure 8. It was found that the tensile and flexural strength generally tended to decrease as the BFA filler loading increased. The values of the tensile and flexural strength of the composites with $25 \mathrm{wt} . \%$ untreated BFA particles were $44.03 \times 10^{6}$ and $76.14 \times 10^{6} \mathrm{~Pa}$, versus $47.93 \times 10^{6}$ and $81.26 \times 10^{6} \mathrm{~Pa}$, respectively, for surface-treated particles. The reduction in the tensile and flexural strength of the composites with treated BFA were likely caused by the decreasing interfacial area in PLA matrix as the filler concentration increased ${ }^{[7,9]}$. Figure 9 shows the fracture surfaces of the PLA/BFA composites with untreated and surface-treated BFA particles. It can be seen that in the case of untreated BFA, voids and pores within the PLA matrix are present, as shown in Figure 9a. This presence may be due to the agglomeration of silica-based BFA filler,
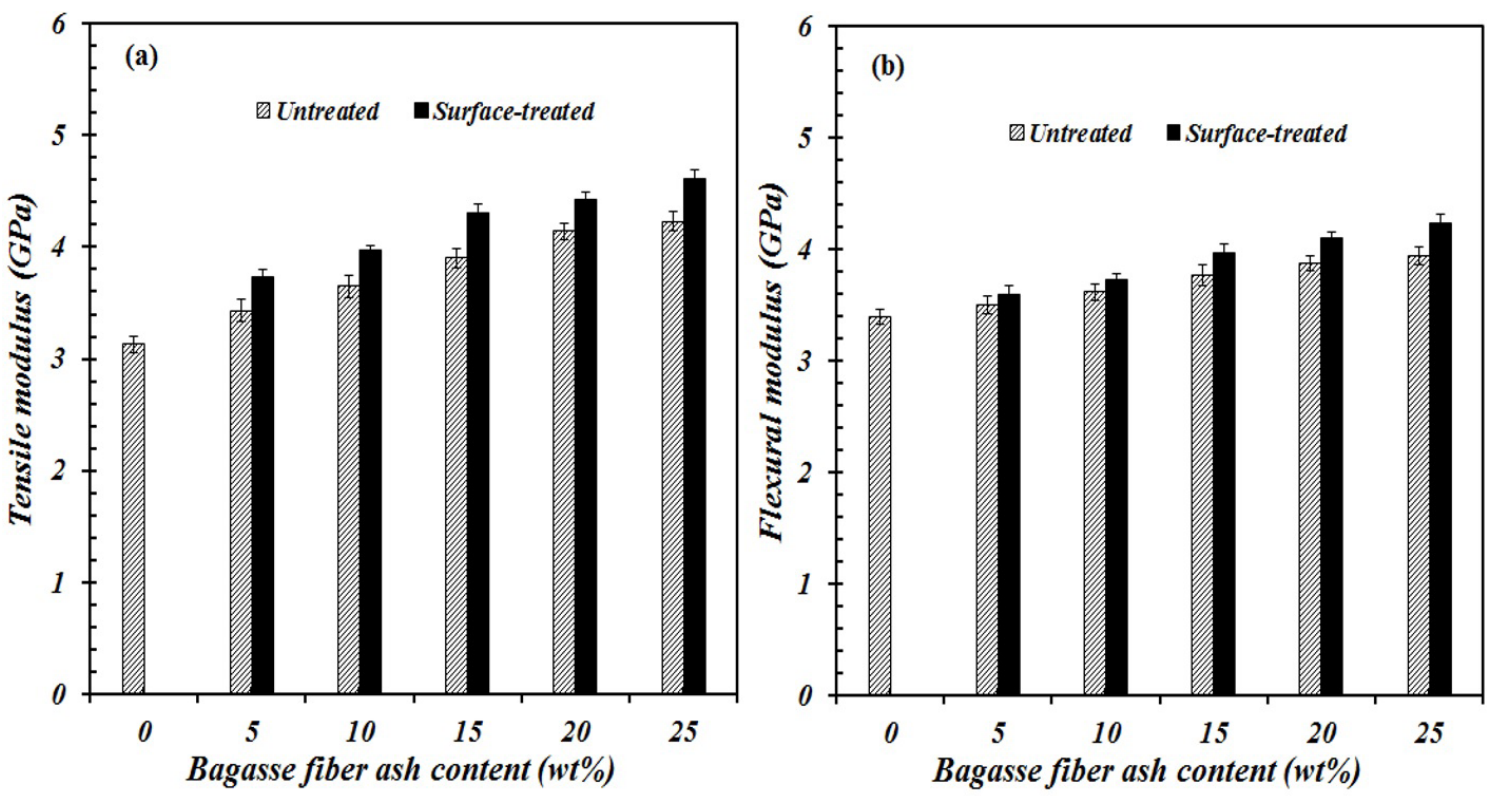

Figure 7. Effect of bagasse fiber ash content on tensile modulus (a) and flexural modulus (b) for PLA/BFA composites with untreated and surface-treated BFA particles. 

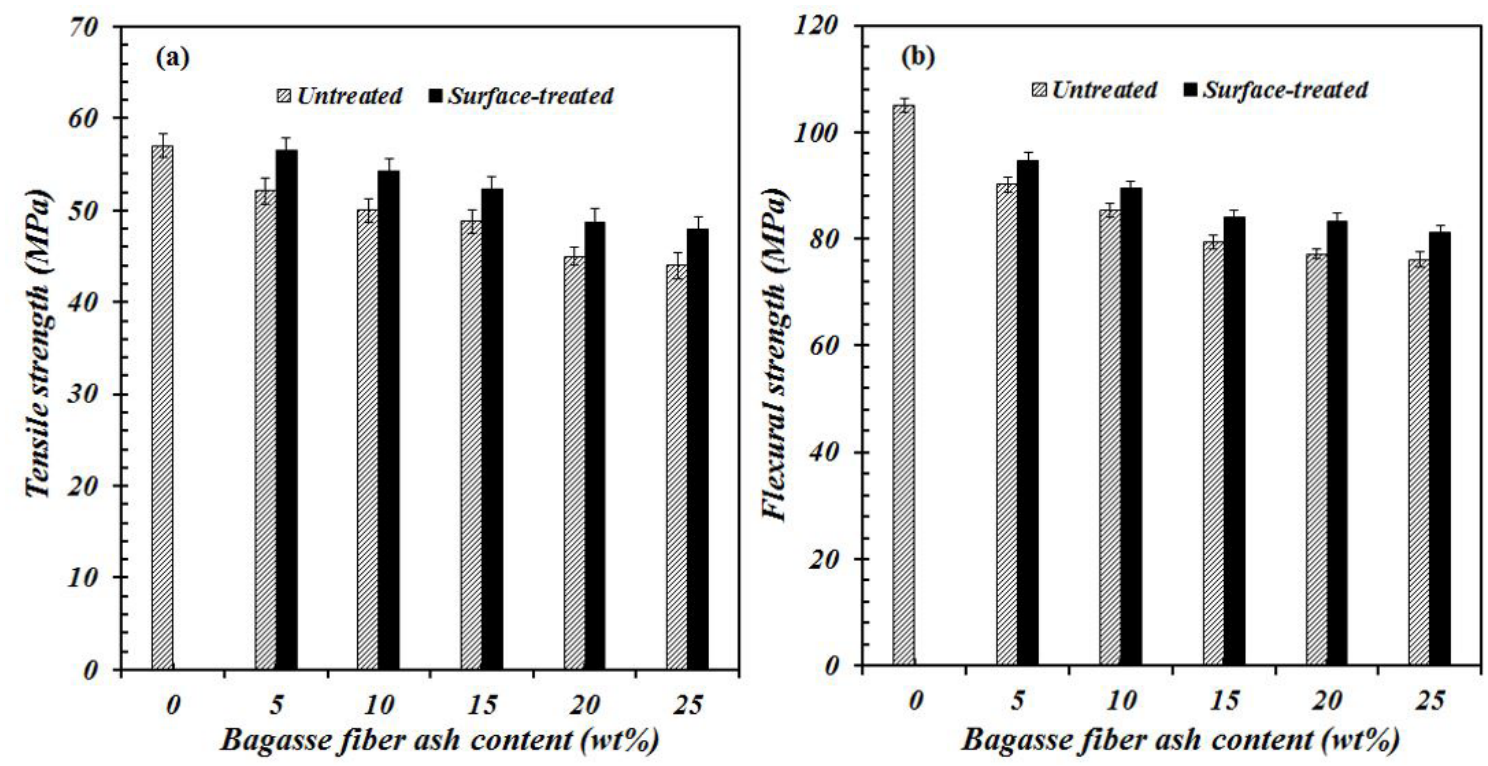

Figure 8. Effect of bagasse fiber ash content on tensile strength (a) and flexural strength (b) for PLA/BFA composites with untreated and surface-treated BFA particles.

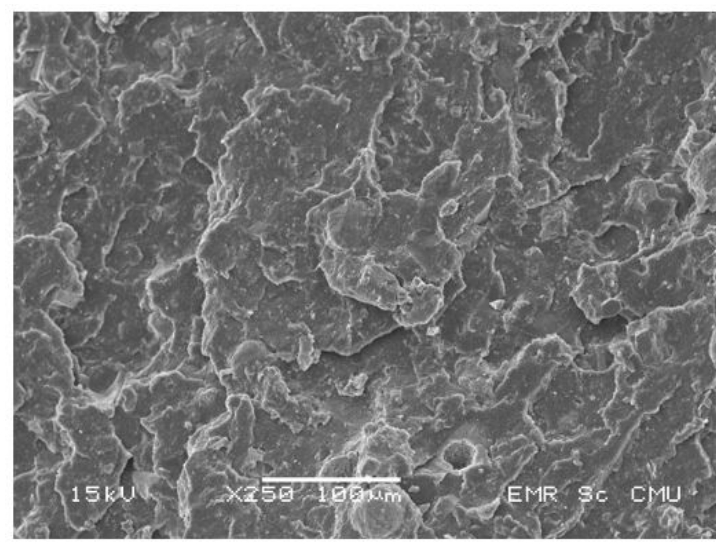

(a)

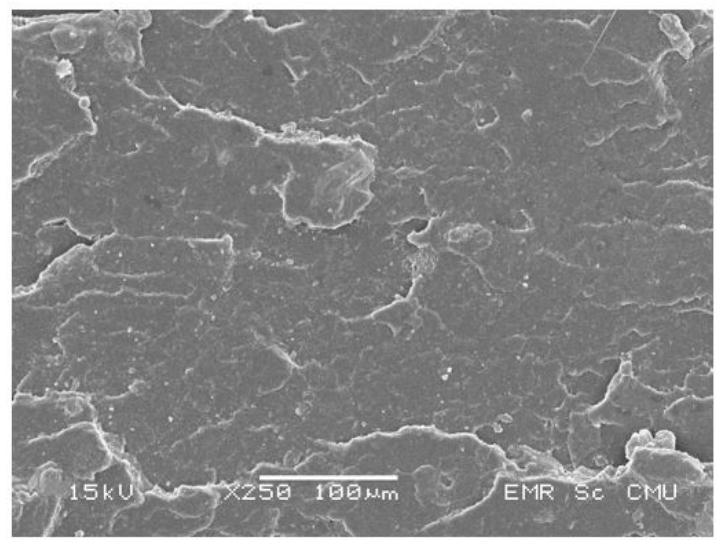

(b)

Figure 9. SEM micrographs of PLA/BFA composites with $25 \mathrm{wt} \%$ of untreated (a) and surface-treated (b) BFA particles.

resulting in the incompatibilities between the hydrophobic PLA and hydrophilic BFA particles ${ }^{[9,19]}$. The surface-treated BFA particles significantly improved their compatibility between the PLA matrix and BFA particles, and the matrix was well bonded to the BFA particles, leading to a smoother fracture surface than that of untreated particles, as shown in Figure 9b. Figure 10 illustrates the impact strength of the PLA/BFA composites with untreated and surface-treated BFA particles.

As can be seen, the impact strength of both composite systems tended to rise with increasing BFA filler content. This was because as the BFA content increased, more interfaces existed on the cracked path, which then led to absorbtion of more energy. The value of the impact strength of the composite with $25 \mathrm{wt}$ \% untreated BFA particles was $4.42 \mathrm{~kJ} / \mathrm{m}^{2}$, versus $4.86 \mathrm{~kJ} / \mathrm{m}^{2}$ for surface-treated particles.

The results of hardness values are shown in Figure 11, the hardness values of the biocomposites increase because of greater rigidities of the filler. The value of Shore D hardness of the composite with $25 \mathrm{wt} . \%$ for untreated and treated BFA particles was 86.1 and 88.3 , respectively.

\subsection{Water absorption}

Figure 12 shows the results of water absorption of the PLA/BFA composites after 2 weeks with untreated and surface-treated BFA particles. Neat PLA has more hydrophobic characteristics than biocomposites and therefore 


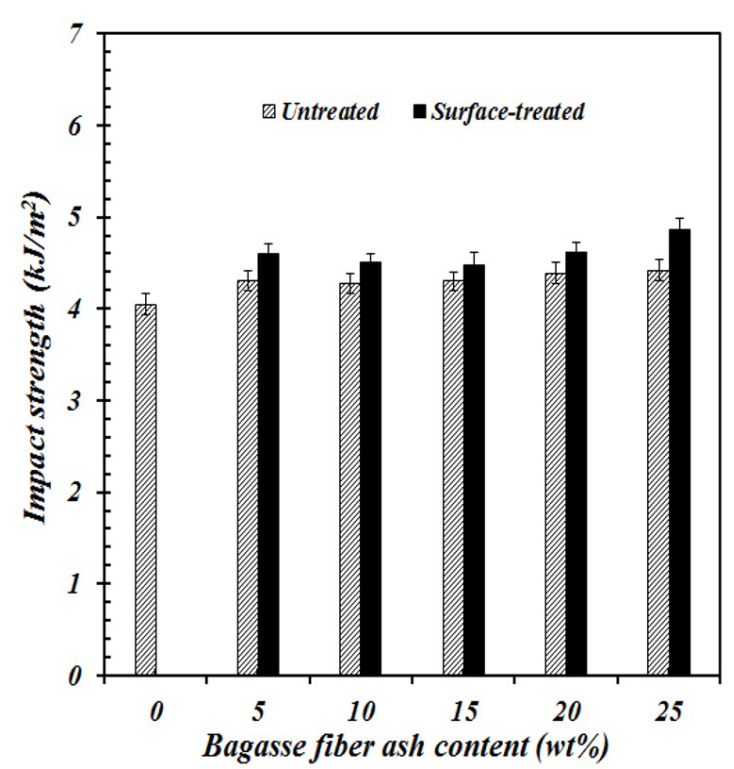

Figure 10. Effect of bagasse fiber ash content on impact strength for PLA/BFA composites with untreated and surface-treated BFA particles.

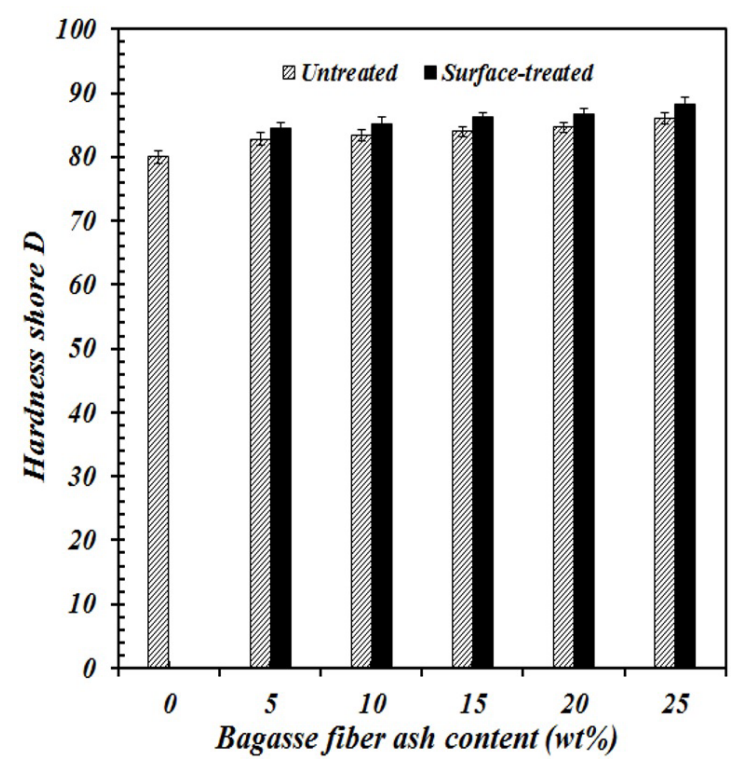

Figure 11. Effect of bagasse fiber ash content on hardness for PLA/BFA composites with untreated and surface-treated BFA particles.

absorbs less water. The addition of BFA particles into the polymeric matrix obviously contributes to more efficient water absorption because of its hydrophilicity, allowing the water to diffuse within the samples. The surface-treatment of BFA particles significantly reduced water absorption of the composites compared to the untreated ones. This view could be supported by Saenghirunwattana et al. ${ }^{[20]}$ who stated that the chemical surface-treated with silane coupling agent increased the hydrophobicity of the fibers due to improving a strong interfacial adhesion between the fiber and polymeric matrix.

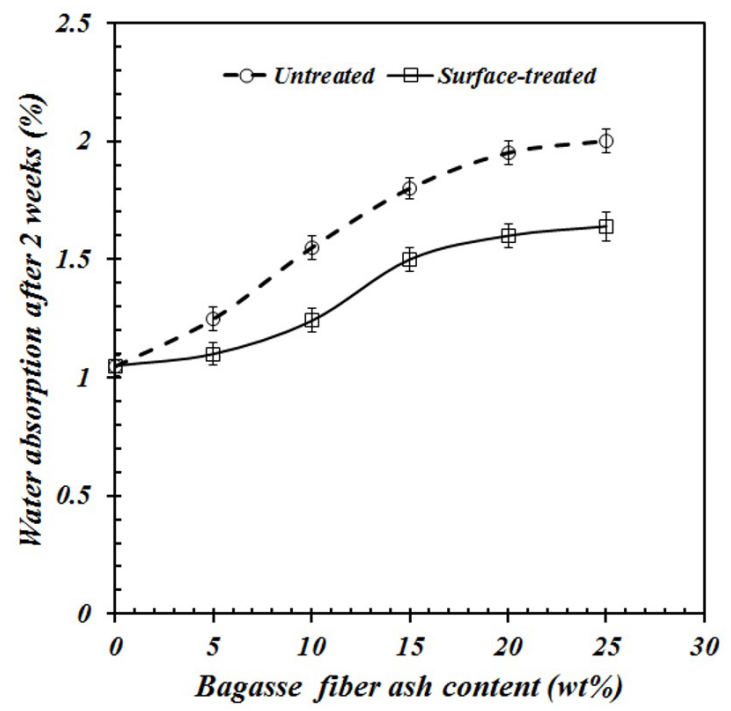

Figure 12. Water absorption of PLA/BFA composites after 2 weeks with untreated and surface-treated BFA particles.

\section{Conclusions}

This research presents the study of the effects of surface-treated silica based bagasse fiber ash on the melt rheological and swell behavior, and mechanical properties and water absorption of biocomposites. The flow behavior studies demonstrated the neat molten PLA and PLA/BFA composites with untreated and surface-treated BFA particles exhibited a shear thinning behavior. The melt viscosity of the biocomposites with surface-treated BFA particles was higher than that of the untreated ones. The viscosity of the composite melts decreased with increasing BFA content and shear rate. The extrudate swell of sample materials increased with increasing wall shear rate in a non-linear manner, whereas it reduced with increasing BFA content and die temperature. The extrudate swell tended to be suppressed when surface-treated BFA particles were used. Silane treated BFA composites showed an improvement in their mechanical properties (tensile and flexural modulus, impact strength and hardness), and exhibited significantly reduced water absorption, as compared to the untreated composites. The tensile and flexural strength for both composite systems tended to decrease with increasing BFA content. The BFA particles added to the neat PLA showed an increase in tensile and flexural modulus, impact strength and hardness values of the composites.

\section{Acknowledgements}

The authors thank the Rajamangala University of Technology Lanna for financial support throughout this work through RMUTL's grant number 2/2558. Special thanks also go to Kaset Thai International Sugar Corp Co., Ltd. (Nakhonsawan, Thailand) and Behn Meyer Chemical (T) Co., Ltd. (Bankok, Thailand) for kindly providing the raw materials. 


\section{References}

1. Arao, Y., Fujiura, T., Itani, S., \& Tanaka, T. (2015). Strength improvement in injection-molded jute-fiber-reinforced polylactide green-composites. Composites. Part B, Engineering, 68, 200206. http://dx.doi.org/10.1016/j.compositesb.2014.08.032.

2. Yuqiong, X., Min, Y., \& Jinping, Q. (2009). Melt rheology of poly (lactic acid) plasticized by epoxidized soybean oil. Wuhan University Journal of Natural Sciences, 14(4), 349-354. http:// dx.doi.org/10.1007/s11859-009-0413-4.

3. Sawpan, M. A., Pickering, K. L., \& Fernyhough, A. (2011). Improvement of mechanical performance of industrial hemp fibre reinforced polylactide biocomposites. Composites. Part A, Applied Science and Manufacturing, 42(3), 310-319. http:// dx.doi.org/10.1016/j.compositesa.2010.12.004.

4. Peltola, H., Pääkkönen, E., Jetsu, P., \& Heinemann, S. (2014). Wood based PLA and PP composites: Effect of fibre type and matrix polymer on fibre morphology, dispersion and composite properties. Composites. Part A, Applied Science and Manufacturing, 61, 13-22. http://dx.doi.org/10.1016/j. compositesa.2014.02.002.

5. Cordeiro, G. C., Toledo, R. D., Fo., Fairbairn, E. M. R., Luis, M. M. T., \& Oliveira, C. H. (2004). Influence of mechanical grind on the pozzolanic activity of residual sugarcane bagasse ash. In International RILEM Conference on Use of Recycled Materials in Building and Structure (p. 731-740). Bagneux, France: RILEM Publications Sarl.

6. Office of Cane and Sugar Board. (2015). Report on total cane crushing and sugar production 2014/2015. Bangkok, Thailand: Office of Cane and Sugar Board.

7. Agunsoye, J. O., \& Aigbodion, V. S. (2013). Bagasse filled recycled polyethylene bio-composites: Morphologicaland mechanical properties study. Results in Physics, 3, 187-194. http://dx.doi.org/10.1016/j.rinp.2013.09.003.

8. Aigbodion, V. S., Hassan, S. B., \& Agunsoye, J. O. (2012). Effect of bagasse ash reinforcement on dry sliding wear behavior of polymer. Materials \& Design, 33(1), 322-327. http://dx.doi.org/10.1016/j.matdes.2011.07.002.

9. Sitticharoen, W., Chainawakul, A., Sangkas, T., \& Kuntham, Y. (2016). Rheological and mechanical properties of silica-based bagasse-fiber-ash-reinforced recycled HDPE composites. Mechanics of Composite Materials, 52(3), 421-432. http:// dx.doi.org/10.1007/s11029-016-9594-z.

10. Kanking, S., Niltui, P., Wimolmala, E., \& Sombatsompop, N. (2012). Use of bagasse fiber ash as secondary filler in silica or carbon black filled natural rubber. Materials \& Design, 41, 74-82. http://dx.doi.org/10.1016/j.matdes.2012.04.042.
11. Awal, A., Rana, M., \& Sain, M. (2015). Thermorheological and mechanical properties of cellulose reinforced PLA biocomposites. Mechanics of Materials, 80, 87-95. http://dx.doi. org/10.1016/j.mechmat.2014.09.009.

12. Dangtungee, R., Petcharoen, K., Pinijsattawong, K., \& Siengchin, S. (2012). Investigation of the rheological properties and die swell of polylactic acid/nanoclay composites in a capillary rheometer. Mechanics of Composite Materials, 47(6), 663-670. http://dx.doi.org/10.1007/s11029-011-9246-2.

13. Muksing, N., Nithitanakul, M., Grady, B. P., \& Magaraphan, R. (2008). Melt rheology and extrusion swell of organobentonitefilled polypropylene nanocomposites. Polymer Testing, 27(4), 470-479. http://dx.doi.org/10.1016/j.polymertesting.2008.01.008.

14. Liang, J. Z. (2008). Effects of extrusion conditions on dieswell behavior of polypropylene/diatomite composite melts. Polymer Testing, 27(8), 936-940. http://dx.doi.org/10.1016/j. polymertesting.2008.08.001.

15. Intawong, N., Udomsom, S., Sugtakchan, K., \& Sitticharoen, W. (2015). Influence of flow pattern development at die entrance and inside annular die on extrudate swell behavior of NR compound. Polímeros: Ciência e Tecnologia, 25(5), 508-513. http://dx.doi.org/10.1590/0104-1428.2021.

16. Dangtungee, R., Yun, J., \& Supaphol, P. (2005). Melt rheology and extrudate swell of calcium carbonate nanoparticle-filled isotactic polypropylene. Polymer Testing, 24(1), 2-11. http:// dx.doi.org/10.1016/j.polymertesting.2004.08.006.

17. Liang, J. Z. (2002). The melt elastic behavior of polypropylene/ glass bead composites in capillary flow. Polymer Testing, 21(8), 927-931. http://dx.doi.org/10.1016/S0142-9418(02)00036-3.

18. Liang, J. Z., Yang, J., \& Tang, C. Y. (2010). Die-swell behavior of $\mathrm{PP} / \mathrm{Al}(\mathrm{OH})_{3} / \mathrm{Mg}(\mathrm{OH})_{2}$ flame retardant composite melts. Polymer Testing, 29(5), 624-628. http://dx.doi.org/10.1016/j. polymertesting.2010.03.014.

19. Dharmalingam, U., Dhanasekaran, M., Balasubramanian, K., \& Kandasamy, R. (2015). Surface treated fly ash filled modified epoxy composites. Polímeros: Ciência e Tecnologia, 25(6), 540-546. http://dx.doi.org/10.1590/0104-1428.2152.

20. Saenghirunwattana, P., Noomhorm, A., \& Rungsardthong, V. (2014). Mechanical properties of soy protein based "green" composites reinforced with surface modified cornhusk fiber. Industrial Crops and Products, 60, 144-150. http://dx.doi. org/10.1016/j.indcrop.2014.06.010.

Received: Jan. 20, 2017

Revised: Apr. 12, 2017

Accepted: May 12, 2017 